Article

\title{
Saward's Concept of the Representative Claim Revisited: An Empirical Perspective
}

\author{
Petra Guasti * and Brigitte Geissel \\ Research Unit Democratic Innovations, Goethe University Frankfurt, 60323 Frankfurt, Germany; \\ E-Mails: guasti@soz.uni-frankfurt.de (P.G.), geissel@soz.uni-frankfurt.de (B.G.) \\ * Corresponding author
}

Submitted: 22 March 2019 | Accepted: 22 July 2019 | Published: 24 September 2019

\begin{abstract}
Representation is a process of making, accepting, or rejecting representative claims (Disch, 2015; Saward, 2014). This groundbreaking insight challenged the standard assumption that representative democracy can be reduced to elections and activities of elected representatives (Pitkin, 1967). It broadened the scope of representative democracy to encompass representation activities beyond those authorized by elections, transformed our thinking and provided a new perspective, putting claims and their reception into the center. This paradigm shift erased the distinction between elected and nonelected representatives and disclosed the potential of non-elected actors' claims to represent (Andeweg, 2003; Kuyper, 2016; Rosanvallon \& Goldhammer, 2008; Saward, 2006, 2009; Van Biezen \& Saward, 2008). In spite of this lively debate, we identify an important gap in the literature: while this paradigmatic shift inspired many authors, conceptual frameworks that can be applied for systematic empirical analysis of real-life cases are missing. In this article, we fill this gap and propose frameworks for assessing and validating a variety of real-life claims. Our study provides empirical substance to the ongoing theoretical debates, helping to translate the mainly theoretical 'claim approach' into empirical research tools. It helps to transform the conventional wisdom about what representation can (not) be and shines a new light on the potential future of (claims on) representation.
\end{abstract}

\section{Keywords}

democracy; representation; representative claim; Saward; typology

Issue

This article is part of the issue "Rethinking Representation: Representative Claims in Global Perspective", edited by Petra Guasti (Goethe University Frankfurt, Germany) and Brigitte Geissel (Goethe University Frankfurt, Germany).

(C) 2019 by the authors; licensee Cogitatio (Lisbon, Portugal). This article is licensed under a Creative Commons Attribution 4.0 International License (CC BY).

\section{Introduction}

Contemporary representative democracies are under considerable strain. Political parties and elected representatives are failing to keep their monopoly on (formal) representation, and allegations of misrepresentation are omnipresent. At the same time, a multitude of non-elective actors increasingly make claims of representation. In response, political actors, as well as political theory, have started to rethink and to transform political representation and representative democracy.

Saward's book on 'The Representative Claim' was the starting point for this transformation (Disch, 2015). Its insights challenged the core assumptions that democracy can be reduced to elections and activities of the elected representative. ${ }^{1}$ It rejected the "idea that representation is first and foremost a given, factual product of elections" (Saward, 2006, p. 298). It doubts the standard no-

\footnotetext{
${ }^{1}$ Even Pitkin (2004) described in her more recent work that "representation has supplanted democracy instead of serving it. The representatives act not as agents of the people but simply instead of them" (p. 339). "The arrangements we call 'representative democracy' have become a substitute for popular self-government, not its enactment" (p. 340).
} 
tion of representation-a given constituency has a given, stable set of interests, which an elected claim maker implements (Schaap, Thompson, Disch, Castiglione, \& Saward, 2012). Accordingly, the idea that a political party is elected to push through these allegedly given interests is obsolete. Elections are no longer a guarantee of representation. It also broadened the scope of representation beyond elections and governing institutions (cf. Montanaro, 2017). This approach, which Disch (2015, p. 487) identified as one of the crucial "conceptual innovation[s] in the analysis of representative politics" of the last decades, considers representation as neither a characteristic of a political system nor as guaranteed by elections.

Instead, representation is considered a dynamic process "of making...accepting, or rejecting representative claims" (Disch, 2015; Saward, 2014, p. 726). Claims and their receptions-acceptance or rejection-are placed at the forefront of democratic theory of representation (in this article we do not refer to the debate whether a claimed constituency is constructed by the claim-maker or a priori existing; see Disch, 2015). Moving beyond formal authorization and accountability of elections also triggers a search for new ways and mechanisms to assess self-appointed representatives and their claims (de Wilde, 2019; Montanaro, 2017).

The paradigmatic change of the constructivist turnpointed out by Dovi (2017) as "by far, one of the most important shifts in the literature on representation"revealed the potential of claims by non-elected actors' to represent a wide range of constituencies. As a result, the multitude of claim-makers generates a cacophony of representative claims rejecting elected representatives (for example 'Not in my name'); on behalf of affected groups ('Mothers against gun violence'); or on behalf of abstract normative schemes ('Dignity, respect and justice for all!') (cf. Andeweg, 2003; Disch, van de Sande, \& Urbinati, 2019; Kuyper, 2016; Montanaro, 2017; Rosanvallon \& Goldhammer, 2008; Saward, 2006, 2009; Van Biezen \& Saward, 2008).

The focus on claims "allows the analysis of nonelected representatives which do not show up on the radar in the traditional focus on elections" (de Wilde, 2013 , p. 278) and encouraged scholars to reflect also on claims made by self-selected claim-makers (e.g., Kuyper, 2016; Montanaro, 2017; Urbinati \& Warren, 2008; Warren, 2001). This emphasis enables us to see that "democracy is far from dead or over in the era of globalization" (de Wilde, 2019, p. 16). Representation is no longer contained in the formal representative arenas. The dynamic processes of claim making, as well as acceptance and rejection of claims is all around.

At a time of crisis for representative democracy, the constructivist turn changed the way we think about representation and representative democracy:
Mansbridge teaches us that democratic representation should not be conceived as a monolithic concept. Democratic representation should no longer be treated as consisting simply in a relationship between elected officials and constituents within her voting district. We should refer to the multiple forms of democratic representation. (Dovi, 2017)

The constructivist literature allows us to take into account claims made by a variety of actors in different arenas, as well a variety of mechanisms of accepting claims (cf. Montanaro, 2017). It also enables us to focus on previously understudied dimensions of representation-such as the aesthetic representation approach of Ankersmit (2002) and Hamilton (2014) and to redefine representation as "a general heuristic for the understanding of political reality" (Näsström, 2006, p. 326; cf. Phillips, 1995; Mansbridge, 1999).

Although the constructivist turn in the study of representation inspired many authors (see Schaap et al., 2012), conceptual frameworks for the systematic empirical analysis of real-life cases are limited. ${ }^{2}$ In this article, we address this need. When representation is claimmaking, and elections are one, but not the only authorization mechanism, we need a new conceptual and analytical framework to grasp the cacophony of claims as well as their acceptance or rejection. It is crucial to develop conceptual and analytical tools to study claims of representation, because many self-selected representatives challenge elected representatives and the statusquo of representative democracy (see also de Wilde, 2019; Guasti \& Almeida, 2019).

The primary objective of our article is the development of conceptual frameworks for identifying, conceptualizing, and categorizing the variety of real-life new claims on representation and reflecting on alternative mechanisms of acceptance. We aim at answering questions like: How can we conceptually grasp and empirically capture the multitude of claims of representation? How can we typologize claims in order to cover a variety of different claims in real-life cases? How can we examine the acceptance of claims of representation in empirical studies of real cases, if the standard mechanism-acceptance via elections-is challenged (see similar Castiglione, 2012, 2017)?

This article provides empirical substance to the ongoing theoretical debate, helping to translate the up to now mainly theoretical 'claim approach' into tools for empirical analysis and thus helping to understand political practice and current real-life developments. Three steps are required to achieve these goals: 1 ) the development of an empirically applicable typology of claims on representation; 2) the development of a framework that enables measurement of how different types of claims of representation can be accepted or rejected; and 3) a test of both conceptual tools on a real-life case.

\footnotetext{
2 For main contribution see de Wilde $(2013,2019)$ and the special issue of the Journal of European Public Policy, 20(2), 2013, on 'The representative turn in EU studies,' which partly alludes to representative claims.
} 
Starting with Saward's approach and later analytical and conceptual refinements of the claims approach, we applied an iterative approach for this endeavor. Beginning deductively with the theoretical basis (Bäckstrand, Kuyper, Linnér, \& Lövbrand, 2017; de Wilde, 2013; Disch, 2011; Disch, van de Sande, \& Urbinati, 2019; Montanaro, 2012, 2017; Saward, 2006, 2010) we added an inductive procedure based on systematic empirical research. With this mixture of deductive and inductive processes, we were able to develop frameworks that can be applied to a variety of real-life cases, which differ with respect to: topic; time frame (different point in time and lengths); location (local, state and federal level); and actors (elected, delegated, self-appointed). We examined cases currently popular in the literature on new forms of democracy (participative budgeting procedures, councils for minorities and direct democratic procedures), as well as debates taking place in parliaments, where claims of representation are prominent (debates on quota rules for women, claims of representation by new, anti-establishment parties or voting rights for non-citizens).

In our case studies in Germany, we collected primary data made public by political institutions (protocols and documentation, online information, steno protocols of parliamentary debates) and print media (articles, interviews) as well as social media (Twitter). However, since our research is embedded in an international research project, covering similar cases in France, Brazil, India, and China, we sought to broaden the applicability of our framework beyond the German cases (see Joschko \& Glaser, 2019). First results from Brazil indicate applicability in cross-national studies (see Guasti \& Almeida, 2019). Our frameworks are applicable to all kinds of claims across the world.

Methodologically we build upon the Representative Claim Analysis, based on de Wilde $(2013,2019)$ as well as on former methodological considerations by Koopmans' and Statham's (1999), which we adapted for our study. Our analysis combines content and discourse analysis and makes use of exploratory approaches like text mining for quantification and validation of claims (for more on this approach see Joschko \& Glaser, 2019).

The article proceeds as follows: in the first section we discuss current research gaps, in the second section we develop a typology of claims on representation, in the third section we outline a conceptual approach allowing us to examine the acceptance or rejection of different types of claims. In the fourth section we apply the typology and conceptual framework for assessing acceptance and rejection of claims to one of our cases.

Most authors speak about "representative claims" or "claims of representation." However, in our empirical research, we noticed that in most real-life cases actual claims of representation, in which a claim-maker explicitly claims to represent a certain constituency, e.g.,
"I represent women," are rare. More often a claim maker only implicitly insinuates to speak for a claimed constituency or does not even mention a claimed constituency and only makes a proclamation e.g., "park benches are needed." To cover all these different claims, we apply the term "claims on representation", which we see as better capturing the variety of claims.

\section{Claims of Representation: Research Gaps}

Several gaps in the literature can be detected, which motivated our study:

First, the proliferating reasoning of political theorists like Saward or Disch about claims on representation has remained abstract (Disch, 2015; Dryzek \& Niemeyer, 2008; Montanaro, 2012, 2017; Mulieri, 2013; Näsström, 2011; Saward, 2006, 2010, 2016). It is mainly the theoretical contribution, which have been the focus of contemporary debates (Disch, 2008; Dutoya \& Hayat, 2016; Kuyper, 2016; Thompson, 2012). Although it was acknowledged that "we need to look closely at how, and by whom 'representative claims' are made, received, and judged" (Saward, 2010, p. 1), the theoretical concepts are rarely applied empirically (cf. Kuyper, 2016; Montanaro, 2012, 2017; Saward, 2009).

A few authors-de Wilde (2013, 2019), Koopmans and Statham (1999, 2010), Kuyper (2016), Severs (2010, 2012), and most recently Heinisch and Werner (2019) started the systematic empirical analysis. The main empirical study that has developed a quantitative approach is the work by de Wilde and colleagues (de Wilde, 2013; de Wilde, Koopmans, \& Zürn, 2014; and the most recent advanced by de Wilde, 2019), who developed the 'representative claims analysis' - a combination of Saward's theoretical notions with the method of content analysis (Koopmans \& Statham, 1999, 2010). However, de Wilde's approach mainly limits itself to the analysis of claims by social movements and other collective actors in the media (Kleinnijenhuis \& Rietberg, 1995; Kriesi \& Trechsel, 2008). ${ }^{3}$ In de Wilde's work, the focus is on claim makers, the justification of claims, and the quality of claims (de Wilde, 2013, 2019, p. 9). However, the types of claims are not differentiated.

Second, to empirically capture the cacophony of claims, we need both empirical and conceptual tools. So far, a typology that can structure the field is missing (see for ideal types Saward, 2008; Sintomer, 2013). Most studies focus on randomly selected examples to illustrate their abstract theoretical arguments. These 'custom tailored' examples, such as the overused claim of Bono representing Africans (Montanaro, 2012; Saward, 2006), neglect myriad real-life cases (Montanaro, 2012, 2017; Severs, 2010, 2012). However, without a typology of real-life claims, the applicability and inference of the claims approach will remain limited.

\footnotetext{
${ }^{3}$ The added value of the claims analysis method includes the capture of addressees, object actors and framing Addressees, according to Koopmans and Statham (1999), are political actors other than the claimants whom the claimant is calling upon to enact his or her claim. They are often executives or other authoritative collective actors with the formal capability to realize the demands voiced in claims.
} 
Third, existing studies often conflate the two stages of a) claim-making and b) reception. ${ }^{4}$ Constructivist scholars broadened the scope of representation to include both elected and self-selected representatives; and reject the notion of elections as a sole authorization mechanism. While the number of empirical studies on claim-making is growing (de Wilde, 2013, 2019; Heinisch \& Werner, 2019; Severs, 2010, 2012), and significant conceptual progress was made to develop alternative authorization mechanisms (Kuyper, 2016; Montanaro, 2017), these two stages of claim-making and reception often got conflated. To conceptually disentangle the two stages, we need to conceptually grasp the variation of claims, and their reception.

\section{Claims on Representation: A New Typology}

This section develops a typology of claims on representation. We start with a discussion of the definition of claims on representation and then proceed to the elements we identified as helpful when identifying a claim.

Various definitions of claims on representation with different layers of complexity were put forward in the literature (e.g., Montanaro, 2017; Saward, 2010, p. 38). Most authors refer to Saward's general definition that a "representative claim" is "a claim to represent or to know what represents the interests of someone or something." (e.g., de Wilde, 2013, 2019; Montanaro, 2017). More detailed definitions, consisting of five dimensions, added a 'referent' and thus ended up with the following definition: "A claim-maker of representations puts forward a subject, which stands for an object that is related to a referent and is offered to an audience" (Saward, 2010). However, the debate did not stop here. Some authors suggested adding more elements and distinctions, such as "affected interests" (Montanaro, 2017) and "justification" (de Wilde, 2013, 2019), while eliminating some of Saward's original categories. For example, de Wilde (2013) rejected Saward's theoretical distinction between a 'maker' and a 'subject' as "not a fruitful distinction from an empirical inquiry point of view" (de Wilde, 2013, p. 284).

Our empirical research showed that the standard definitions put forward by political theorists require some adaption:

- Claims are often incomplete and do not include all elements outlined in the literature; claims of representation with explicit reference to a claimed constituency are very rare, most claim-makers only insinuate implicitly that they speak for someone. For example, in the participatory budgeting procedure, we found mainly proclamations e.g., "More bike lanes are needed in this city." In order to capture all kinds of claims, which refer to a claimed constituency or not, we differentiated between different types of constituency (see Tables 1 and 2).

- In some of our real-life cases, the claim-maker explicitly claimed a linkage between herself and the claimed constituency, e.g., "I am like you," "I know what you need because I live in the same town." In some cases, this link is only constructed implicitly: "Seniors like me need park benches." We decided to take claimed linkages (and their absence) into account. It makes a vast difference for the acceptance of claims, if the claimed linkage can be accepted by the claimed constituency or if a claim is made without a linkage.

- In real-life cases, claim makers often accuse elected representatives of not representing their constituency. i.e., of misrepresentation. In other word, claim makers referred to representatives, who would be expected to represent someone or something-but do not. Accordingly, in contrast to de Wilde's critique (2013), we utilize Saward's differentiation between 'claim maker' and 'subject,' (for more on claims of misrepresentation see Guasti \& Almeida, 2019).

- Our empirical analysis showed that the claimed constituency is often not a 'subject,' but a normative scheme, e.g., justice, freedom. For example, in participatory budgeting procedures, many citizens made a claim in the name of the 'common good.' Even in parliamentary debates on topics like quota rules or voting rights for foreigners the claim-makers mostly referred to normative schemes (see Joschko \& Glaser, 2019). Accordingly, we distinguish between two types of the claimed 'constituency'-human beings and normative schemes (cf. Mansbridge, 2011; Pitkin, 1967, 2004; Runciman, 2007). We recognize that claims to normative schemes appeal to an actual human constituency-i.e., to those sharing the values of justice and freedom. However, the reception of this claim will be different-in order to accept or reject a claim e.g., to 'justice' the member of the audience ought to first assess whether justice is grounds for accepting a claim (cf. Ankersmit, 2002; Montanaro, 2017 on affected interests; Näsström, 2006 on aesthetic aspects of representation).

Essential elements of claims on representation are depicted in Table 1.

\subsection{The Typology}

In the literature on representation, there is no lack of typologies (Mansbridge, 2003; Pitkin, 1967; Young, 1986, p. 357,2002 , pp. 125-127). However, this is not the case in the literature on claims on representation.

\footnotetext{
${ }^{4}$ Disch (2015) differentiates three stages, i.e., claim making, reception and normative reception. Kuyper (2016) applied a specific way of reception based on normative yardsticks requiring normative expert judgments. We do not follow this path but want to measure the receptions taking place in real life cases.
} 
Table 1. Elements of claims on representation.

\begin{tabular}{lll}
\hline Element & Definition & Differentiation \\
\hline Claim makers & who speaks & $\begin{array}{l}\text { (i.) elected representatives, } \\
\text { (ii.) delegated representatives and } \\
\text { (iii.) non-elected representatives. }\end{array}$ \\
\hline Claimed representative & $\begin{array}{l}\text { who is expected to act on behalf } \\
\text { of the claimed constituency }\end{array}$ & $\begin{array}{l}\text { (i.) claim-maker identical with a claimed representative; } \\
\text { (ii.) claim maker and claimed representative are different; } \\
\text { (iii.) absent. }\end{array}$ \\
\hline Claimed constituency & $\begin{array}{l}\text { on whose behalf subject claims } \\
\text { to speak }\end{array}$ & $\begin{array}{l}\text { (i.) human being(s), interests; } \\
\text { (ii.) normative scheme(s), values; }\end{array}$ \\
\hline (iii.) absent. \\
\hline Claimed linkage & $\begin{array}{l}\text { the claimed connection between } \\
\text { the claim maker and the claimed } \\
\text { constituency }\end{array}$ & $\begin{array}{l}\text { (i.) referenced (either explicitly or implicitly); } \\
\text { (ii.) denied; } \\
\text { (iii.) absent. }\end{array}$ \\
\hline
\end{tabular}

Generally, typologies are useful in empirical research to serve "as conceptual tools to simplify and order complex social phenomena such as political systems" (Lehnert, 2007, p. 62). In order to achieve this goal types should ideally be "mutually exclusive and exhaustive" (George \& Bennett, 2005, p. 238). In other words, every case should fall into one category, and one category only, and within-type variation should be small. We tried to develop a parsimonious typology that can be applied to various empirical contexts (Sartori, 1970).

Typologies can be derived deductively or inductively (Lehnert, 2007, p. 67). Our typology is based on theoretical consideration but was developed inductively by examining a variety of case studies including three democratic innovations: Council for Foreigners (Kommunale Ausländervertretung- KAV). in Frankfurt, which focuses on representation of non-citizens; a referendum in Hamburg on school reform, which showed a clash between elected and self-selected representatives; and participative budgeting in the city of Münster; as well as three parliamentary debates: on quotas, on voting rights and on anti-establishment critique by the radical right Alternative for Germany (AfD) (for details see Appendix; for analysis of the quota debate see Joschko \& Glaser, 2019; for the analysis of the parliamentary debate see Guasti \& Almeida, 2019).

Referring to the elements of the claims discussed above enables us to identify key semantic features of claims on representation and to operationalize the distinctive semantic features of four types of claims (see Table 2).

Table 2. Types of claims.

\begin{tabular}{llll}
\hline Types of Claims & Constituency & Linkage & Example \\
\hline CLAIM OF REPRESENTATION & referenced & referenced & We [AfD] represent the \\
claim maker speaks for/on behalf of the claimed & & German people. \\
constituency and indicates a linkage between & &
\end{tabular}

constituency and indicates a linkage between

$\mathrm{him} /$ herself and claimed constituency

\section{CLAIM OF MISREPRESENTATION \\ claim maker accuses another representative of not representing the claimed constituency and denies a linkage between other representative and claimed constituency}

\section{CLAIM OF INTERESTS/VALUES}

claim maker speaks of interests and values, referring explicitly/implicitly to a claimed constituency without indicating any linkage to claimed constituency

PROCLAMATION
claim maker states a proposal without referring to a
claimed constituency and without indicating any
linkage to claimed constituency

SPD [Social democrats] no longer represent the workers.

Source: The authors. 


\section{Acceptance or Rejection of Claim: Conceptual Framework for Empirical Analysis}

Claims on representation only work if they are accepted ("acknowledged") (Lord \& Pollak, 2013; Saward, 2010). "Without an audience, a representative claim cannot have an impact on politics and society and is therefore meaningless for democracy" (de Wilde, 2013, p. 284; also Montanaro, 2017; Rehfeld, 2006). Disch (2015) has already suggested:

First is whether or not to accept the subject of the claim - the representative-as representing its object (i.e., itself) in the sense of acting and speaking on its behalf. Second is whether to accept the idea of the object that the claim puts forth, meaning that it must decide whether it recognizes itself as it is portrayed by the claim. (Disch, 2015, p. 494)

Since the standard mechanism for the acceptance of claims, i.e., elections, are not the sole authorization mechanism, the literature on representation and representative claims have started to discuss the issue in a more differentiated way (Disch, 2015; Dryzek \& Niemeyer, 2008; Kuyper, 2016; Montanaro, 2012, 2017; Saward 2016; Severs, 2012). However, the state of the art is limited (for more critique see Joschko \& Glaser, 2019). In order to demonstrate the problem and to provide a conceptual solution we 1) discuss definitions of acceptance, 2) introduce an empirically significant differentiation of the 'accepting actors', and 3) develop a framework, which takes into account that different types of claims require different mechanisms of acceptance.

The acceptance and rejection of claims is central to the constructivist literature (Disch, 2015; Montanaro, 2017; Saward, 2006). Classical literature uses the term authorization, which is reserved for elections and eligible actors, i.e., members of the government, members of parliament and president (Pitkin, 1967). After the constructivist turn had broadened the scope of representation beyond the monopoly of elected representatives, this limitation was broken, and other mechanisms are discussed (Montanaro, 2017). In the wake of this shift, a variety of different terms evolved, for example: acknowledgement, reception, perception, absorption, engagement, legitimacy, accountability, authenticity, legitimation, resonance, responsiveness, judgement, congruence, affectedness, resemblance, expertise, assessment, credibility, recognition, evaluation, inclusivity, or consequentiality (Disch, (2015); Dryzek \& Niemeyer, 2008; Kuyper, 2016; Montanaro, 2012, 2017; Saward (2016); Severs, 2012). As Saward put it, "Representative claims only work, or even exist, if 'audiences' acknowledge them in some way, and are able to absorb or reject or accept them or otherwise engage with them" (Saward, 2008, p. 303).
We identify and address three gaps in the constructivist literature:

1) All of these terms are used but rarely operationalized, which makes the empirical application difficult. Two examples might illustrate this problem: the term legitimacy mostly refers to legitimacy as perceived by citizens, but it is also confused with input, throughput or output legitimacy. The term authenticity serves as an umbrella term for a variety of different aspects, such as noncoercion, generalizability (Kuyper, 2016) or honesty. For now, we go 'back to the roots' and focus on the acceptance or rejection of a claim (c.f. Disch, 2008).

2) Being interested in the acceptance or rejection of a claim, we have to raise the question of who is the accepting or rejecting actor. Kuyper (2016) suggested that experts decide on the validity of a claim, based on preset normative claims. Dovi (2017) states that "The represented should have an ultimate say in judging the claims of the representative. The task of the representative is to create claims that will resonate with appropriate audiences". Montanaro sees the identification of "affected interests" by the audience as a precursor to "public judgement and democratic justification" (2017, p. 13).

Saward (2010, p. 186) and Disch (2015, p. 494) also distinguish between different actors vis-à-vis acceptance and rejection of the claims. Saward (2010, p. 186) differentiated between the "claimed constituency" and the "effective audience" "with resources of influence," defined as actors who can make an effective contribution, for example, mass media, powerful advocacy groups, celebrities or experts. Disch (2015) also emphasized the need to differentiate: " $[A]$ claim succeeds so long as it is assessed favorably by the audience; it is democratically legitimate, however, only when it is accepted or taken up by a constituency" (p. 494). She mentions "structural differences of power" between the claimed constituency and the "audience", with the "audience" enabling success (p. 495).

Thus, both the claimed constituency and a second entity, which plays a role and has some power ('effective audience' in Montanaro, 2017, or as we call it, 'decisionmaking authority'), need to be conceptually separated (for more debate on constituency and audience see Guasti \& Almeida, 2019; for a quantitative approach to identification of audience and the assessment of acceptance and rejection see Joschko \& Glaser, 2019). ${ }^{5}$

3) Empirically, the claimed constituency can be identified and operationalized, if (explicitly) referenced by the claim maker. For example, "I am speaking for the students at our university." In contrast, what Saward (2010) calls an "effective audience" is too vague and too complex to be taken into account in empirical research (de Wilde, 2013). It would be empirically challenging to detect and to examine all potentially "effective audiences" (for an innovative approach within the framework of substantive representation see Kroeber, 2018).

\footnotetext{
${ }^{5}$ de Wilde (2012, p. 284) rejected the distinction between audience and constituency as "needlessly complicated," and eliminates the audience from his empirical analysis. In contrast, we consider the differentiation between claimed constituency and another 'powerful' entity as crucial.
} 
In our framework we distinguish between acceptance and rejection by the claimed constituency and by the relevant decision-making authority. Constituency can be referenced directly (i.e., to human beings) or indirectly (to normative schemes). A decision-making authority can be, for instance, a parliament, a mayor or in case of a referendum (such as the school referendum in Hamburg) the citizenry.

A framework of analysis taking into account the different types of claims and 'accepting actors' (claimed constituency, decision-making authority) is described in Table 3.

The empirical application of this framework is demanding. How can we find out whether the claimed constituency and the relevant authority accepts or rejects the respective type of claim? Which mechanism can be applied to 'accept' the different types? The following debate can only be exemplary (for a novel approach to authorization of claims by self-selected representatives see Montanaro, 2017).

Considering the claim of representation by an elected representative (for example in a plenary debate in parliament), the standard mechanism for acceptance are the subsequent elections (cf. Mansbridge, 2017; Pitkin, 1967, 2004). However, even elections are no ultimate proof for the acceptance of a claim of representation. During their electoral campaign, parliamentarians make multiple claims, and their re-election does not necessarily indicate that the voters accepted every claim the parliamentarian made.

Considering claims of representation by non-elected claim makers, the situation is even more complicated. For example, we do not exactly know whether the advocacy group claiming to represent German farmers, the German Farmer Association (GFA), is accepted by its claimed constituency. However, the relevant authority, i.e., the German government, accepts the GFA's claim to represent farmers and actively engages with it in all matters relevant to farmers and agriculture. At the same time, some German farmers reject the GFA's claim and seek to represent their views (for example on the need to a more sustainable farming) and their values (sustainability) themselves.

What about the acceptance of claims of misrepresentation? Contestations of existing representatives, as well as policies and politics are widespread among advocacy groups and emerging anti-establishment political forces. Parties (such as the AfD) or social movements (such as the Yellow Vests movement in France) reject the formal authorization (elections) of the elected representatives. Simultaneously, they are not willing to wait until the next elections, to vote their political opponents out of office, and use claims of misrepresentation to deny their role as representatives - in the parliament (AfD parliamentarians, see Guasti \& Almeida, 2019), online (see Joschko \& Glaser, 2019), and on the streets (the Yellow Vest protestors).

Many advocacy groups depart from the accusation that representatives or other advocacy groups do not represent the constituency they are supposed to represent. There is, for example, a variety of women's advocacy groups which accuse female representatives as well as other women's advocacy groups that they do not represent women, but "only businesswomen", "only mothers", or "only female workers." These claims of misrepresentation are challenging to evaluate, and up to now, there are no useful mechanisms for measuring the acceptance of claims of misrepresentation.

Furthermore, some claims of misrepresentation, for example by the German AfD, that 'governments betray the silent minority', can, hardly be tested. Others, for example, the claim that the Social Democrats (SPD) no longer represent German workers can be checked by examining, whether workers vote for the SPD, or alternatively, the extent to which SPD pursues worker-related policies (cf. Guasti \& Almeida, 2019; cf. Kroeber, 2018).

Considering claims of interests/values, it is relatively difficult to assess whether the relevant constituency accepts the claim, but it is possible to detect whether the relevant authority accepts the claim. For example, a group of teachers can claim to know what is right for children. The children can hardly reject or accept this claim as a group. Whether the claimed constituency accepts the claim can only be examined via surveys. In the case of the claim by teachers, this would be a survey of preferences by pupils (and may be parents). But the city council, as a relevant authority, can accept this claim.

Considering the proclamation' there is no claimed constituency. The claim maker (merely) claims that for example park benches are needed. In the context of participative budgeting, a counter proclamation can be made that there are enough park benches. No constituency is mentioned in these proposals and the identification of affected audience is complex. Is it every in-

Table 3. Acceptance/rejection of different claims.

\begin{tabular}{lcc}
\hline Type of claim & $\begin{array}{c}\text { A. Acceptance/rejection by } \\
\text { the claimed constituency }\end{array}$ & $\begin{array}{c}\text { B. Acceptance/rejection by the } \\
\text { relevant authority }\end{array}$ \\
\hline CLAIM OF REPRESENTATION & yes (direct) & yes \\
\hline CLAIM OF MISREPRESENTATION & yes (direct) & yes \\
\hline CLAIM OF INTERESTS/VALUES & yes (indirect) & yes \\
\hline PROCLAMATION & no (not applicable) & yes \\
\hline
\end{tabular}

Source: The authors. 
habitant of the city, city visitors, people who occasionally sit on benches, or those who find benches important for others, or simply aesthetically pleasing? In the absence of linkage to constituency, the proclamation cannot be accepted by the relevant constituency. Again, it is relatively easy to examine whether the relevant authority accepts the respective claim. The relevant authority which decides can be, for example, the city council, but also the participants in participative budgeting, a citizens' jury, or (for something larger than park benches) the whole constituency in a referendum.

Finally, we want to point out the issue of the 'acceptance hierarchy of claims'. This issue deserves significant attention in future research, but we can only mention it here. In standard theories of representation, it is assumed that the acceptance of a claim maker by the respective constituency is the 'highest level': if the claim maker is accepted (i.e., elected or re-elected), all claims by this claim maker are expected to be accepted by the constituency. The reality, however, looks quite different. A claim maker can be accepted (she is elected), but her proposals as an elected claim-maker can be rejected within her constituency. Furthermore, an elected representative does not only represent her voters, but everybody in her district-those who accepted her claimmaking and voted for her, and those who did not. Furthermore, a candidate can be rejected (not elected), but a survey might show that the majority of her electoral districts supports her claim. Our analytical framework enables empirical researchers to differentiate the acceptance of the different types of claims without falling into the trap of the 'acceptance hierarchy of claims.'

\section{An Empirical Test}

To empirically test our typology and our framework, we apply them to the claims raised by the Frankfurt Council of Foreigners-an example of the electoral representation of non-citizens. In this part, we proceed in three steps. First, we briefly introduce the case study and our methodology. Second, we apply our typology of claims on representation to show the variation of claims made-claims of representation, claims of misrepresentation, claims of interests/values, and proclamations. We also demonstrate the relevance of our distinction between human beings and normative schemes. Third, we apply our conceptual framework for empirical analysis of acceptance and rejections of claims made by this Council. We show that our typology and conceptual framework provide a useful tool to analyze and compare claims of representation and their acceptance.

\subsection{Case Study Description and Methodology}

We have tested the empirical validity of our typology by applying it to six German debates (for details on the six case studies see Appendix). The case study presented here is the KAV. KAV is a body for the local representation of foreigners in the city of Frankfurt (Germany). The Hesse law stipulates that the non-citizen residents elect KAV for a five-year term. KAV can, however, only make so-called 'requests' and 'questions' to the municipality (municipal government and municipal bureaucracy). We have analyzed both categories and they contain all four types of claims on representation.

What makes the case of KAV particularly interesting from the point of view of representation is the size and heterogeneity of the Frankfurt non-citizens population. $27.7 \%$ of Frankfurt residents are non-citizens. With more than 150 nationalities, this group is exceptionally heterogeneous $^{6}$. For a significant part of the non-citizen population of Frankfurt, the non-EU citizens, KAV is the only way to participate politically ( $37 \%$ of the non-citizen population in 2014, i.e., 73,000 Frankfurt inhabitants).

We have analyzed 284 claims raised by KAV between 2006 and 2017. Combining elements of content and discourse analysis, we proceed in three steps to identify:

1. The claim makers; in the case of KAV, the rules stipulate that only KAV as a whole can be a claim maker vis-à-vis the municipal government and municipal bureaucracy;

2. The claimed constituency, using both, open coding and assigning the category of human being or normative schemes;

3. The claimed linkage between the subject (KAV) and the object (claimed constituency).

Based on the combination of the object (claimed constituency) and linkage, we subsequently applied our typology and identified the type of claim.

Two members of the research team codded all claims separately, using pre-agreed categories. Intercoder reliability test was performed regularly, including all coded claims (Cohen's kappa, $\mathrm{K}$, where complete agreement $K=1$ ). In all intercoder reliability tests, the value of Cohen's kappa was above 0.85 . Those items, where coders did not reach an agreement, were subsequently discussed and recoded.

\subsection{Application of the Typology}

of Representative Claims to the Case of KAV in Frankfurt Over time, the number of claims remained relatively constant (mostly between 17 and 35 claims per year), but the types of claims fluctuate (Figure 1). Overall, the most frequently used type of claim is claim of interests/values $(52 \%)$, and the least used category is claim of misrepresentation (11\%).

Regarding the claimed constituency (Figure 2), we found that the majority of claims (58\%) are related to human beings. Human beings as the claimed constituency

\footnotetext{
${ }^{6}$ The KAV elections struggled with the meager turnout, both absolutely and compared to other cities in Hesse. In 2015 only $6.2 \%$ eligible voters took part in the KAV elections.
} 


\section{COGITATIO}

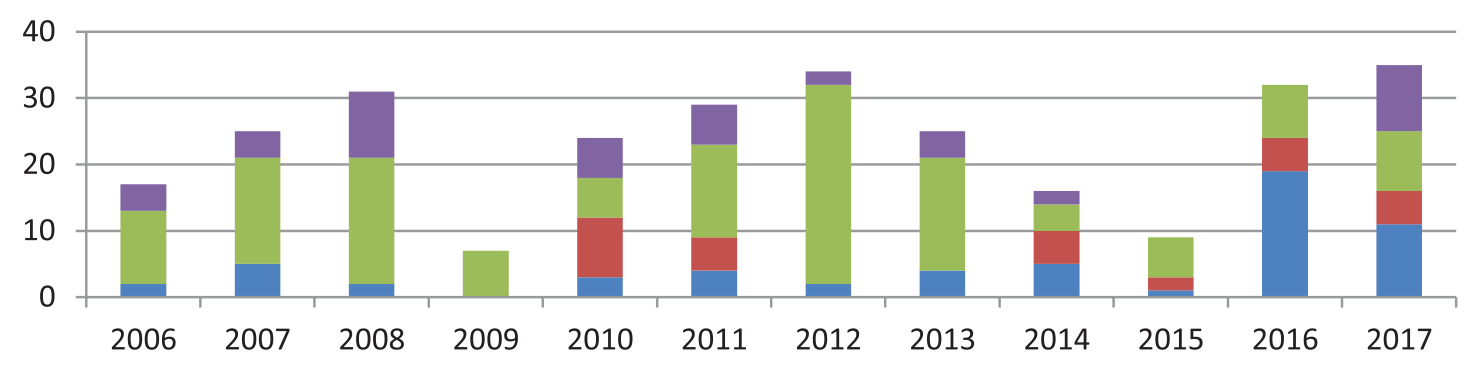

claim of representation $\square$ claim of misreresentation $\square$ claim of interests/values $\square$ proclamation

Figure 1. Types of claims by KAV Frankfurt (2006-2017). Note: $N=284$. Source: The authors.

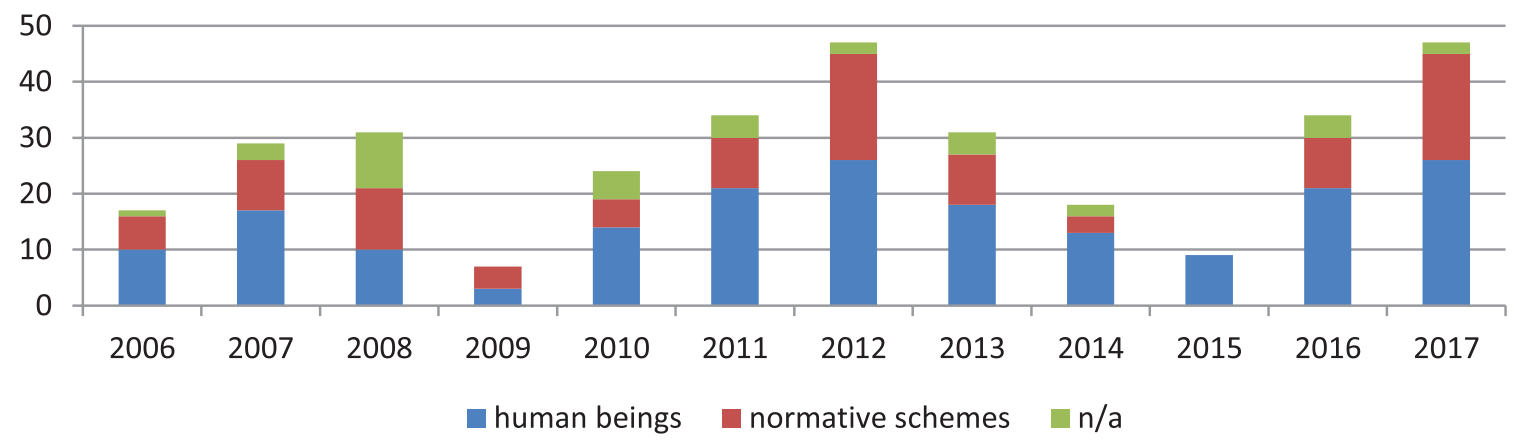

Figure 2. Claimed constituency by KAV (2006-2017). Note: $N=324$ (some claims include more than one claimed constituency). Source: The authors.

are most often foreigners/migrants, non-German speakers, Muslims, asylum seekers, refugees, migrant children/youth, migrant associations, non-Christian patients in hospitals and KAV itself. Normative schemes (32\%) are most often inclusiveness, diversity, integration, antidiscrimination, public safety, sustainability, multiculturalism, tolerance, equal treatment, public health and safety, and religious freedom (always vis-à-vis Islam).

A number of claims pertain to the competences of KAV. KAV raises a claim of representation, where it represents itself, in pushing the municipality to enlarge the scope of its competencies.
Conceptually, we see that the distinction of constituency between human being and normative schemes is essential. The use of the category normative schemes enables us to identify the constituency behind these normative schemes; such as here, in our example, where 'religious freedom' is a frame used to push for more accommodation for the Muslim population of Frankfurt.

A claimed linkage was included in $20 \%$ of the claims (claims of representation), absent in $69 \%$ of the claims (claims of interests/values and proclamation) and denied in $11 \%$ of the claims (claim of misrepresentation). Figure 3 summarizes the application of our framework

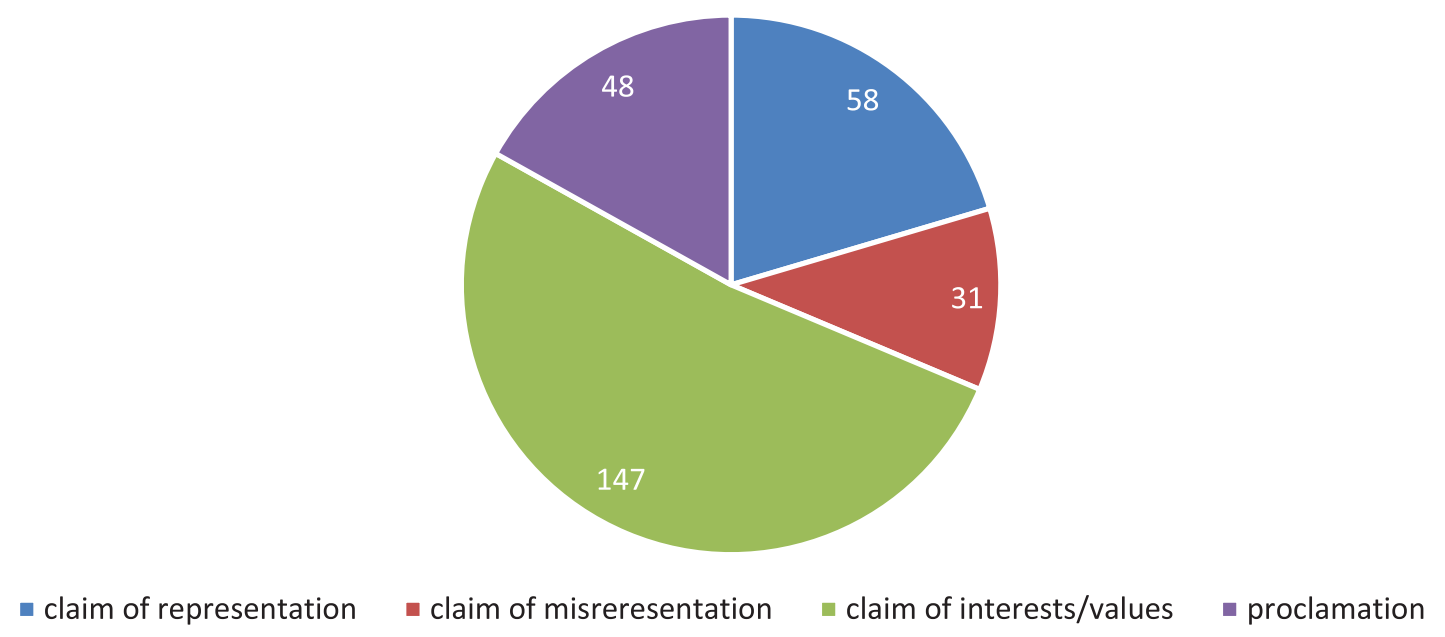

Figure 3. Typology of claims applied to KAV. Note: $\mathrm{N}=284$. Source: The authors. 
to the case of the KAV in Frankfurt. Our typology enables us to better grasp the dynamics of real-life case, in which the claimants not only make assertions about who (and what) they represent, but also accuse others of misrepresentation, assert values and interest, and often make proclamations with little relevance to the notion of representation.

\subsection{Acceptance of Claims}

Regarding KAV authorization via elections (by its intended constituency - the Frankfurt non-citizen population), the KAV turnout has been steadily decreasing over time, reaching $6.2 \%$ in its most recent elections (2015). Given the high degree of reelection for the members of the conservative lists, it is possible to assume that the majority of voters (93.8\%) do not support KAV (claims), only a minority does.

Given the limited competences of KAV, it is essential to analyze not only the claims KAV is making but also the ways to which the decision-making authority, the Frankfurt City Council (FCC), react to KAV's claims (Figure 4). In order to assess the level of acceptance of KAV claims, we traced each claim individually through the process. We found that the majority of KAV claims were processed by the city council (59\%). A significant number of the proposals were rejected (31\%), and a small number accepted (10\%).

The majority of the accepted claims $(\mathrm{N}=16)$ are general and reflect the desire of the FCC to seek an open and inclusive society. These included the introduction of intercultural competence and multilingual staff in the office for seniors to improve access for non-German speaking seniors and to adapt the congratulatory letter for reaching adulthood to include migrants and young adults with two citizenships (to foster integration). Upon KAV request, a bilingual Greek-German school program was not abolished, Neo-Nazi demonstrations banned, and a stricter approach was adopted in order to impede hate crime. Some general changes included, road adjustment, the location of public toilets in the city, and the improvement of the ambiance at the train station.

The majority of the rejected KAV claims $(N=50)$ tend to represent interests of separate (often conserva- tive male-only) KAV groups opposed to integration and seeking to insulate their constituency from integration. Some rejected claims also define KAV as representative of Muslim residents (regardless of their citizenship status). The city council views KAV with growing suspicion (and contempt)-as a Trojan horse of Frankfurt Muslims. Partial interests, which clash with the KAV mission and the integration plan of the city, are rejected, and the perception of KAV as able to represent the interests of the Frankfurt non-citizens population continues to be undermined.

The most contentious rejected request in this term was the 2009 demand for the introduction of the representative (magistrate) for Islam to represent 80,000 Muslims in Frankfurt. A backlash in the media followedthe opponents of KAV called for its abolition, as it does not fulfill its role "to represent all non-citizen inhabitants of the city" (Guasti \& Geissel, 2019).

The high proportion of rejected claims undermines the perception of KAV and its dominant group among the KAV constituency. But, perhaps more importantly, the KAV self-perception as representative of the Turkish minority paints the image of a minority unable to embrace the city's values of diversity and tolerance. In effect, KAV serves as a persuasive argument against the enfranchisement of non-citizens and undermines the potential for their inclusion into mainstream politics.

The application of our framework yields relevant inferences about the functioning of an innovative representative body, and a better understanding of the reasons, why KAV is failing. Our analysis highlights the tension between the roles of the KAV as it is defined in the Hesse Constitution and KAV's self-perception. The former defines KAV as an institution that fosters integration and identifies issues relevant to the non-German population of the city. The latter perceives itself as representatives of a specific religious group-the Muslim population. The overlap between the constituency intended by the Hesse law and the claimed constituency of KAV is getting narrower over time. Subsequently, the number of accepted claims decreases.

Our conceptual framework enables researchers to systematically study representative claims and their acceptance (see also Guasti \& Almeida, 2019; and Joschko

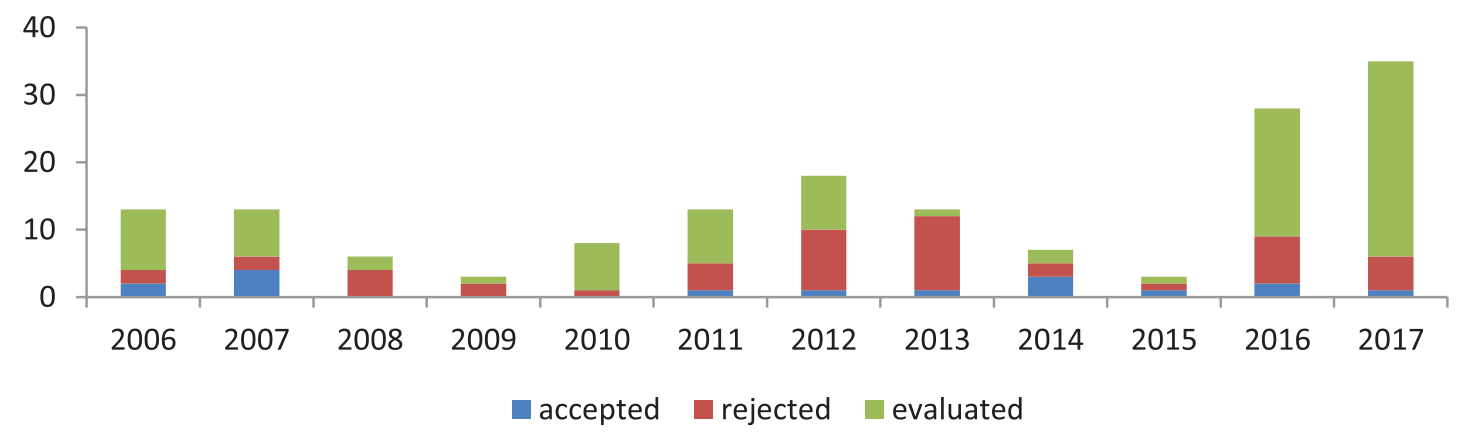

Figure 4. Acceptance of KAV Claims 2006-2017. Note: $N=160$ (excluding questions from the sample and analyzing requests only). Source: The authors. 
\& Glaser, 2019). As the KAV case shows, it facilitates an indepth qualitative analysis of claims over time, and their comparison along the different types and constituencies. With regard to acceptance (and rejection) of claims, we illustrate that the acceptance or rejection by the relevant constituency can and has to be taken into account. Furthermore, the effects of any claims depend on the assessment of the relevant authority. Finally, our case study hints to the problem of gaps between the representatives and the represented.

\section{Conclusion}

The constructivist turn in political representation challenged and changed our understanding of representative democracy (Disch, van de Sande, \& Urbinati, 2019). The theoretical literature on claims expanded significantly beyond Saward, yet it remained highly abstract and often detached from the cacophony of real-life claims and their empirical research (Disch, 2008; Dryzek \& Niemeyer, 2008; Kuyper, 2016; Montanaro, 2012, 2017; Severs, 2010, 2012).

In this article, we develop conceptually and empirically applicable frameworks to conceptualize and to analyze claims of representation. We show that different types of claims exist and that different mechanisms are or can be applied to accept or reject these claims.

Based on our analyses of several real-life cases of democratic innovations and parliamentary debates in Germany we, first, developed a comprehensive typology which allows for capturing the variety of reallife claims by elected as well as non-elected claimmakers. Analyzing a variety of real-life claims, we detected that explicit claims of representation ("I represent") are rather rare within real-world cases. Based on our empirical findings we distinguish four types of claims: the 'standard' claim of representation (with explicitly claimed constituency and claimed linkage); the claim of misrepresentation, the claim of interest (with implicitly claimed constituency without claimed linkage), and proclamation (neither claimed constituency nor linkage). These four types capture the cacophony of all claims on representations.

Second, we provided a framework for examining the mechanisms of acceptance for the different claim types. Analyzing different real case studies, it turned out thatas suggested by Saward and others - the differentiation between claimed constituency and decision-making authority is necessary.

Third, we discussed that the mechanism of acceptance of claims depends on the type of claimed constituency (human beings or normative scheme) as well as the claimed linkage (claimed, denied, absent). For example, claims by an animal advocacy group, claiming to represent "justice for farm animals" (normative schemes) cannot be accepted directly. First, the affected constituency has to identify itself within the audiencei.e., all those for whom "justice for farm animals" is important (for an excellent discussion of affected interests see Montanaro, 2017). At the same time, this claim can be accepted by a relevant decision-making authority (Ministry of Agriculture) who accepts the advocacy group's claim to represent "justice for farm animals" as valid and invites the group to submit a proposal on improving the well-being of farm animals.

Our frameworks enable better understanding of claims and their reception, but they also offer a new impulse for re-thinking the basic assumptions about representative democracy. Whereas representative democracy is based on the premise that only one mechanism of acceptance, namely, election is needed (Pitkin, 1967), the reality is more complicated. The public sphere is full of claim makers, elected and self-selected, making claims. Some of these claims have the potential to revitalize representative democracy. Others challenge not only the status quo, but as de Wilde $(2019$, p. 16) shows use highly sophisticated claims to challenge the liberal order as whole.

In contrast to other authors (Kuyper, 2016) we do not propose (normative) criteria for acceptance of a claim. On the contrary, we are interested in the mechanisms of acceptance and rejection by the respective constituency and the decision-making authorities in real-life cases. We see our study as a jigsaw piece in the current search for the transformation of representative democracy. We hope to enrich the debate by systemizing current claims on representation and by providing new insights into mechanisms of acceptance or rejection of the different types of claims. This is just the beginning of a broader research agenda. The next step for future research is the evaluation of different types of claims and an attempt at systematization of the mechanisms of acceptance.

\section{Acknowledgments}

We thank the DFG and ANR for their kind funding of the research project "(New) Political Representative Claims: A Global View (France, Germany, Brazil, India, China)". We also thank the three anonymous reviewers, and Stefan I. Lindberg for their comments and recommendations.

\section{Conflict of Interests}

The authors declare no conflict of interests.

\section{References}

Andeweg, R. B. (2003). Beyond representativeness? Trends in political representation. European Review, 11(2), 147-161.

Ankersmit, F. R. (2002). Political representation. Palo Alto, CA: Stanford University Press.

Bäckstrand, K., Kuyper, J. W., Linnér, B. O., \& Lövbrand, E. (2017). Non-state actors in global climate governance: From Copenhagen to Paris and beyond. Envi- 
ronmental Politics, 26(4), 561-579.

Castiglione, D. (2012): Giving Pitkin her due: What the 'representative claim' gets right, and what it risks missing. Contemporary Political Theory, 11(1), 118-122.

Castiglione, D. (2017). Representative claim: A double ambiguity. Paper presented at the ECPR Conference, Oslo.

de Wilde, P. (2013). Representative claims analysis: Theory meets method. Journal of European Public Policy, 20(2), 278-294.

de Wilde, P. (2019). The quality of representative claims: Uncovering a weakness in the defense of the liberal world order. Political Studies, 1-22. https://doi.org/ 10.1177/0032321719845199

de Wilde, P., Koopmans, R., \& Zürn, M. (2014). The political sociology of cosmopolitanism and communitarianism: Representative claims analysis (WZB Discussion Paper No. SP IV 2014-102). Berlin: WZB Berlin Social Science Center.

Disch, L. (2008). The people as 'presupposition' of representative democracy: An essay on the political theory of Pierre Rosanvallon. In Redescriptions: Yearbook of political thought and conceptual history (Vol. 12, pp. 47-72). Münster: LIT Verlag Münster.

Disch, L. (2011). Toward a mobilization conception of democratic representation. American Political Science Review, 105(1), 100-114.

Disch, L. (2015). The 'constructivist turn' in democratic representation: A normative dead-end? Constellations, 22(4), 487-499.

Disch, L., van de Sande, J. J. M., \& Urbinati, N. (Eds.). (2019). The constructivist turn in political representation. Edinburg: Edinburg University Press.

Dovi, S. (2017). Political representation. Stanford Encyclopedia of Philosophy. Retrieved from https:// plato.stanford.edu/archives/win2017/entries/ political-representation

Dryzek, J. S., \& Niemeyer, S. (2008). Discursive representation. American Political Science Review, 102(4), 481-493.

Dutoya, V., \& Hayat, S. (2016). Prétendre représenter [Pretending to represent]. Revue Française de Science Politique, 66(1), 7-25.

George, A. L., \& Bennett, A. (2005). Case studies and theory development in the social sciences. Cambridge, MA: MIT Press.

Guasti, P., \& Almeida, D. (2019). Claims of misrepresentation: A comparison of Germany and Brazil. Politics and Governance, 7(3), 152-164.

Guasti, P., \& Geissel, B. (2019). Do non-citizens represent non-citizens? A contingent 'no'. Manuscript submitted for publication.

Hamilton, L. (2014). Freedom is power: Liberty through political representation. Cambridge, MA: University Press.

Heinisch, R., \& Werner, A. (2019). Who do populist radical right parties stand for? Representative claims, claim acceptance and descriptive representation in the Austrian FPÖ and German AfD. Representation, 1-18. https://doi.org/10.1080/00344893.2019. 1635196

Joschko, V., \& Glaser, L. (2019). A new approach to map and quantify representative claims and measure their validation: A case study analysis. Politics and Governance, 7(3), 137-151.

Kleinnijenhuis, J., \& Rietberg, E. M. (1995). Parties, media, the public and the economy: Patterns of societal agenda-setting. European Journal of Political Research, 28(1), 95-118.

Koopmans, R., \& Statham, P. (1999). Political claims analysis: Integrating protest event and political discourse approaches. Mobilization: An International Quarterly, 4(2), 203-221.

Koopmans, R., \& Statham, P. (Eds.). (2010). The making of a European public sphere: Media discourse and political contention. Cambridge: Cambridge University Press.

Kriesi, H., \& Trechsel, A. H. (2008) The politics of Switzerland: Continuity and change in consensus democracy. Cambridge, NY: Cambridge University Press.

Kroeber, C. (2018). How to measure the substantive representation of traditionally excluded groups in comparative research: A literature review and new data. Representation, 54(3), 241-259.

Kuyper, J. W. (2016). Systemic representation: Democracy, deliberation, and nonelectoral representatives. American Political Science Review, 110(2), 308.

Lehnert, M. (2007). Typologies in social inquiry. In T. Gschwend \& F. Schimmelfennig (Eds.), Research design in political science (pp. 62-82). New York, NY: Palgrave, MacMillan.

Lord, C., \& Pollak, J. (2013). The pitfalls of representation as claims-making in the European Union. Journal of European Integration, 35(5), 517-530.

Mansbridge, J. (1999). Should blacks represent blacks and women represent women? A contingent "yes." The Journal of Politics, 61(3), 628-657.

Mansbridge, J. (2003). Rethinking representation. American Political Science Review, 97(4), 515-528.

Mansbridge, J. (2011). Clarifying the concept of representation. American Political Science Review, 105(3), 621-630.

Mansbridge, J. (2017). Recursive representation in the representative system (Working Paper No. RWP17-045). Cambridge, MA: Harvard Kennedy School. https://doi.org/10.2139/ssrn.3049294

Montanaro, L. (2012). The democratic legitimacy of selfappointed representatives. The Journal of Politics, 74(4), 1094-1107.

Montanaro, L. (2017). Who elected Oxfam? A democratic defense of self-appointed representatives. Cambridge: Cambridge University Press.

Mulieri, A. (2013). Beyond electoral democracy? A critical assessment of constructivist representation in the global arena. Representation, 49(4), 515-527. 
Näsström, S. (2006). Representative democracy as tautology: Ankersmit and Lefort on representation. European Journal of Political Theory, 5(3), 321-342.

Näsström, S. (2011). Where is the representative turn going? European Journal of Political Theory, 10(4), 501-510.

Phillips, A. (1995). The politics of presence. Oxford: Clarendon Press.

Pitkin, H. F. (1967). The concept of representation. Berkeley, CA: University of California Press.

Pitkin, H. F. (2004). Representation and democracy: Uneasy alliance. Scandinavian Political Studies, 27(3), 335-342.

Rehfeld, A. (2006). Towards a general theory of political representation. The Journal of Politics, 68(1), 1-21.

Rosanvallon, P., \& Goldhammer, A. (2008). Counterdemocracy: Politics in an age of distrust. Cambridge: Cambridge University Press.

Runciman, D. (2007). The paradox of political representation. Journal of Political Philosophy, 15(1), 93-114.

Sartori, G. (1970). Concept misformation in comparative politics. American Political Science Review, 64(4), 1033-1053.

Saward, M. (2006). The representative claim. Contemporary Political Theory, 5(3), 297-318.

Saward, M. (2008). Representation and democracy: Revisions and possibilities. Sociology Compass, 2(3), 1000-1013.

Saward, M. (2009). Authorisation and authenticity: Representation and the unelected. Journal of Political Philosophy, 17(1), 1-22.

Saward, M. (2010). The representative claim. Oxford: Oxford University Press.

Saward, M. (2014). Shape-shifting representation. American Political Science Review, 108(4), 723-736.
Saward, M. (2016). Fragments of equality in representative politics. Critical Review of International Social and Political Philosophy, 19(3), 245-262.

Schaap, A., Thompson, S., Disch, L., Castiglione, D., \& Saward, M. (2012). Critical exchange on Michael Saward's 'The Representative Claim'. Contemporary Political Theory, 11(1), 109-127.

Severs, E. (2010). Representation as claims-making. Quid responsiveness? Representation, 46(4), 411-423.

Severs, E. (2012). Substantive representation through a claims-making lens: A strategy for the identification and analysis of substantive claims. Representation, 48(2), 169-181.

Sintomer, Y. (2013). The meanings of political representation: Uses and misuses of a notion. Raisons Politiques, 2(50), 13-34.

Thompson, S. (2012) Making representations: Comments on Michael Sawards 'The Representative Claim.' Contemporary Political Theory, 11(1), 111-114.

Urbinati, N., \& Warren, M. E. (2008). The concept of representation in contemporary democratic theory. Annual Review of Political Science, 11, 387-412.

Van Biezen, I., \& Saward, M. (2008). Democratic theorists and party scholars: Why they don't talk to each other, and why they should. Perspectives on Politics, 6(1), 21-35.

Warren, M. E. (2001). Democracy and association. Princeton, NJ: Princeton University Press.

Young, I. M. (1986). The ideal of community and the politics of difference. Social Theory and Practice, 12(1), $1-26$.

Young, I. M. (2002). Inclusion and Democracy. Oxford: Oxford University Press.

\section{About the Authors}

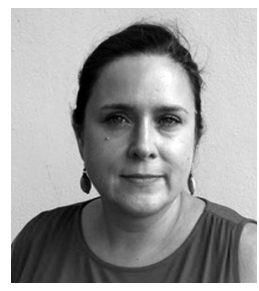

Petra Guasti is an Interim Professor at the Institute of Political Science, Goethe University Frankfurt (Democratic Innovations Unit). She was AY 2018/2019 Democracy Visiting Fellow at the Ash Centre for Democratic Governance and Innovation, Harvard Kennedy School. Her main research focus is democracy, more specifically the growing tension within the system of representative democracy in respect to its legitimacy. Her research appears among others in Democratization, Communist and PostCommunist Studies, European Political Science and East European Politics and Societies and Cultures.

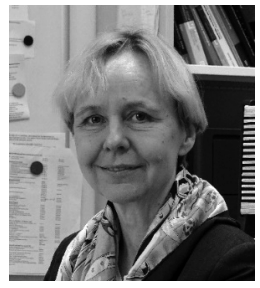

Brigitte Geissel, Goethe University Frankfurt, Professor of Political Science and Political Sociology, Head of Research Unit "Democratic Innovations". Her research interests include democratic innovations, new forms of governance and political actors (new social movements, associations, civil society, parties, political elites, citizens). Recently published in Political Studies Review, Representation, Political Studies, International Political Science Review. 


\section{Appendix}

\begin{tabular}{|c|c|c|c|c|}
\hline \multicolumn{3}{|c|}{ Case description } & \multicolumn{2}{|c|}{ Interim findings } \\
\hline $\begin{array}{l}\text { CLAIMS type } \\
\text { (based on CLAIMS } \\
\text { proposal) }\end{array}$ & Theme & Temporality & claim makers & claimed constituencies \\
\hline $\begin{array}{l}\text { Critique of } \\
\text { (descriptive) } \\
\text { misrepresentation }\end{array}$ & $\begin{array}{l}\text { gender quota } \\
\text { in business }\end{array}$ & 2003-2018 & $\begin{array}{l}\text { Feminists/NGOs/ } \\
\text { academics } \\
\text { Media/business/ } \\
\text { parliamentarians/ } \\
\text { party officials }\end{array}$ & $\begin{array}{l}\text { women in general/with ambitions/ } \\
\text { in business/equality/equal } \\
\text { opportunity/justice/freedom/ } \\
\text { Constitution }\end{array}$ \\
\hline $\begin{array}{l}\text { Critique of } \\
\text { (substantive) } \\
\text { misrepresentation }\end{array}$ & AfD & $\begin{array}{l}2013-2018 \\
\text { (first six } \\
\text { months) }\end{array}$ & AfD leadership & $\begin{array}{l}\text { the German people/the (people) left } \\
\text { behind/the 'Nation'/German destiny/ } \\
\text { historical calling } \\
\text { German democracy }\end{array}$ \\
\hline $\begin{array}{l}\text { Democratic } \\
\text { innovations: } \\
\text { Reclaiming } \\
\text { representation? }\end{array}$ & $\begin{array}{l}\text { Voting rights } \\
\text { for non- } \\
\text { naturalized } \\
\text { residents }\end{array}$ & 1990-2017 & $\begin{array}{l}\text { Political parties/ } \\
\text { Courts/Ministry of } \\
\text { Interior/FOMR/ } \\
\text { NGOs/Non-naturalized } \\
\text { residents }\end{array}$ & $\begin{array}{l}\text { German citizens in general/ } \\
\text { non-naturalized citizens } \\
\text { Constitution/citizenship/participation } \\
\text { integration }\end{array}$ \\
\hline $\begin{array}{l}\text { Representation } \\
\text { without elections: } \\
\text { Participatory } \\
\text { budgeting }\end{array}$ & PB Münster & 2011 & Citizens/Stakeholders & $\begin{array}{l}\mathrm{n} / \mathrm{a} \\
\text { only representation in claims: } \\
\text { proposals for savings }\end{array}$ \\
\hline $\begin{array}{l}\text { Representation } \\
\text { without citizenship: } \\
\text { Council for } \\
\text { foreigners in } \\
\text { Frankfurt }\end{array}$ & KAV Frankfurt & 2006-2017 & KAV as a whole & $\begin{array}{l}\text { foreigners/migrants/non-German } \\
\text { speakers/Muslims/asylum seekers/ } \\
\text { KAV/inclusiveness/integration/ } \\
\text { anti-discrimination/religious freedom } \\
\text { (vis-à-vis Islam). }\end{array}$ \\
\hline $\begin{array}{l}\text { Democratic } \\
\text { innovations: Direct } \\
\text { democracy }\end{array}$ & DD Hamburg & 2008-2010 & $\begin{array}{l}\text { Citizens' initiatives/ } \\
\text { teachers' associations/ } \\
\text { Trade Unions/students' } \\
\text { groups/Hamburg } \\
\text { government/Political } \\
\text { parties }\end{array}$ & $\begin{array}{l}\text { all citizens/all children/all pupils/ } \\
\text { 'entitled' pupils } \\
\text { inclusive educational system }\end{array}$ \\
\hline
\end{tabular}

